\title{
PERANCANGAN APLIKASI ADMINISTRASI DAN PELAYANAN MASYARAKAT PADA KELURAHAN DESA KREYO PEMALANG
}

\author{
Ayu Widia Astuti ${ }^{1}$, Een Juhriah ${ }^{2}$, Maimunnah ${ }^{3}$ \\ Program Studi Informatika, Fakultas Teknik dan Ilmu Komputer, Universitas Indraprasta PGRI \\ Jl. Raya Tengah No. 80, Kelurahan Gedong, Pasar Rebo, Jakarta Timur \\ sasiputricahya@gmail.com¹, eenzuhriah29@gmail.com², queenahakim@gmail.com³
}

\begin{abstract}
Abstrak.
Dalam administrasi dan pelayanan masyarakatnya kelurahan desa Kreyo saat ini masih menggunakan cara manual yaitu dengan media kertas yang dibuat di microsoft word dan tidak adanya data yang terbaru secara cepat karena prosesnya yang lambat dengan itu tujuan penelitian ini adalah untuk membuat sistem aplikasi administrasi dan pelayanan masyarakat pada kelurahan Desa Kreyo, Metode Penelitian yang digunakan pada perancangan aplikasi administrasi \& pelayanan masyarakat ini adalah Grounded Research dengan studi lapangan serta diskusi dengan pihak terkait seperti kepala lurah Desa Kreyo maupun masyarakat sekitar dan juga melakukan dokumentasi untuk mendapatkan informasi yang dibutuhkan. Selain itu peneliti juga melakukan penelitian dengan metode kepustakaan berdasakan refrensi dan berbagai diskusi serta berbagai media yang memuat informasi mengenai segala sesuatu yang menyangkut informasi yang dibutuhkan, Hasil dari penelitian ini adalah Aplikasi yang dapat membantu kemudahan pengarsipan dan pelayanan masyarakat oleh staf kelurahan untuk masyarakat dan pihak yang membutuhkan laporan secara cepat efesien dan efektif.
\end{abstract}

Kata Kunci: Java, Administrasi Masyarakat, Pelayanan Masyarakat, Sistem Informasi

\begin{abstract}
In the administration and public service of Kreyo village is still using manual means that with paper media made in microsoft word and the absence of the latest data quickly because of the slow process with it the purpose of this research is to create an application system of administration and community service in the village of Kreyo Village, Research Method used in the design of administrative applications \& community service is Grounded Research with field studies and discussions with related parties such as the head of kreyo village. and the local community and also do documentation to get the information needed. In addition, researchers also conduct research with library methods based on refrence and various discussions as well as various media containing information about everything related to the information needed. The result of this research is an Application that can help ease archiving and community service by village staff for the community and those who need reports quickly efficiently and effectively.
\end{abstract}

Keyword: Java, Community Administration, public service, information Systems.

\section{PENDAHULUAN}

Setiap instansi pemerintah mempunyai suatu unit yang bertugas dalam bidang administrasi (Mulyadi, 2010). Dalam sebuah instansi pemerintahan misalnya pada suatu pengarsipan dilingkup kelurahan yang memang memerlukan perubahan pengarsipan yang lebih cepat dan efisen. Pada dasarnya kegiatan pengarsipan berfungsi untuk menghasilkan, menerima, mengelola dan menyimpan berbagai surat, laporan formulir dan sebagainya. Kegiatan instansi memerlukan data dan informasi, yang salah satu sumber data tersebut adalah arsip. Arsip merupakan kumpulan informasi dalam bentuk media apapun, yang dibuat dan diterima oleh seseorang yang kemudian akan dikelola oleh suatu instansi dalam rangka pelaksanaan kegiatan pendataan (Moenir, 2011).

Kelurahan desa Kreyo merupakan salah satu instansi pemerintah dalam dunia pelayanan masyarakat yang terdapat di kecamatan Randudongkal kabupaten Pemalang. Dalam administrasi dan pelayanan masyarakatnya kelurahan desa Kreyo masih menggunakan cara manual yaitu dengan media kertas yang dibuat di microsoft word dan tidak adanya data yang terbaru secara cepat karena prosesnya yang lambat. Dengan sitem perngarsipan yang masih di lakukan secara manual juga mengakibatkan kinerja petugas yang kurang efesien dan banyaknya biaya yang akan dikeluarkan apabila pengarsipan tersebut menggunakan media kertas, dan juga akan mempengaruhi dalam pelayanan masyarakatnya karena masyarakat akan lebih sulit untuk mendapatkan data secara cepat dan tepat. Berdasarkan masalah di atas maka peneliti akan melakukan penelitian dengan membuat sistem yang berjudul "Perancangan Aplikasi Administrasi dan Pelayanan Masyarakat 
pada Kelurahan Desa Kreyo Pemalang”. Dari latar belakang yang telah didefinisikan di atas, maka penjabaran rumusan masalahnya yaitu memastikan sistem administrasi dan pelayanan masyarakat desa Kreyo ini berjalan dengan baik untuk sistem perngarsipan. Dan memberikan kemudahan di instansi dalam mengelola data - data di kelurahan desa Kreyo serta agar masyarakat mendapatkan kebutuhan data secara cepat dan efesien dengan tujuan adanya aplikasi administrasi dan pelayanan masyarakat yang terkoneksi dengan database memudahkan petugas untuk mecari data penduduk yang dibutuhkan secara cepat dalam pengelolaan pengarsipan.

\section{PENELITIAN RELEVAN}

Penelitian oleh (Sari, 2016) dengan judul "Perancangan Sistem Informasi pelayanan Masyarakat pada PTSP Kelurahan Ragunan Jakarta Selatan" dari hasil penilitain aplikasi Sistem Informasi pelayanan Masyarakat bertujuan untuk mengetahui Informasi pelayanan Masyarakat pada PTSP Kelurahan Ragunan Jakarta Selatan yang efektif dan efisien. Hasil dari penelitian ini adalah terciptanya Perancangan Sistem Informasi pelayanan Masyarakat pada PTSP Kelurahan Ragunan Jakarta Selatan untuk memudahkan pekerjaan staff dalam pembuatan surat keterangan agar dapat lebih cepat karena tanpa harus meregistrasi surat terlebih dahulu.

Penelitian relevan selanjutnya adalah penelitian oleh (Sutanta, 2013) dengan Judul "Model Integrasi Database Penduduk Indonesia Dengan Berbagai Sistem Informasi Berbasis Komputer" dari hasil penelitian model integrasi mengintegrasi database penduduk dengan basis computer agar memudahkan dalam proses pengarsipan. Hasil dari penelitian ini adalah terciptanya perancangan sistem dengan pengembangan informasi kependudukan, pengembangan dan penggunaan SIN warga Negara Indonesia, kerangka restrukturisasi data sebagai basis sisfonas dan model integrasi SIBK dalam ragam instansi dan database penduduk.

\section{METODE PENELITIAN}

Metode penelitian yang digunakan oleh peneliti adalah metode grounded research yaitu suatu metode penelitian berdasarkan pada fakta dan analisis perbandingan dengan tujuan mengadakan generalisasi empiris, menetapkan konsep, membuktikan teori, mengembangkan teori, pengumpulan dan analisis data dalam waktu yang bersamaan. Dalam riset ini data merupakan sumber teori atau teori berdasarkan fakta. Tahapan digunakan peneliti dalam metode penelitiannya yaitu dengan:

\section{Metode Pendekatan}

Pendekatan dilaksanakan di Kelurahan Kreyo Kota Pemalang untuk pengumpulan data/fakta yang cukup efektif untuk mengetahui proses-proses yang sedang berjalan serta membuat keputusan yang menyangkut lingkungan fisiknya pada suatu kegiatan yang berjalan

2. Wawancara (Interview)

Wawancara yang dilakukan kepada staf pelayanan mengenai permasalahan pengolahan data administrasi untuk mengetahui masalah yang timbul atau dialami langsung oleh orang yang bersangkutan. Dalam kegiatan ini diajukan pertanyaan lisan dalam usaha untuk melengkapi data yang akan diperoleh.

3. Implementasi

Keseluruhan desain pemodelan yang telah dibuat diubah menh=jadi kode-kode program dengan menggunakan aplikasi java netbeans.

4. Pengujian

Pada taha[ ini perancangan perangkat lunak yang telah dibuat direalisasikan sebagai unit program dan sebuah aplikasi desktop

\section{HASIL DAN PEMBAHASAN}

Berdasarkan masalah-masalah yang dihadapi dalam penerimaan, pemrosesan hasil input dan pembuatan hasil laporan pelayanan masyarakat pada kelurahan Kreyo maka peneliti memberikan alternative penyelesaian yaitu:

1. Perancangan aplikasi administrasi pelayanan masyarakat yang terkomputerisasi harus segera dilaksanakan

2. Perancangan database berbasis komputerisasi untuk aplikasi administrasi pelayanan masyarakat sehingga mempermudah penyimpabn data 
3. Perlunya mendidik sumber daya manusia yang terampil agar mampu menjalankan sistem yang ada dengan baik

Aturan bisnis yang diusulkan pada administrasi pelayanan masyarakat pada Kelurahan Desa Kreyo Pemalang adalah sebagai berikut:

1. Bagian administrasi pelayanan masyarakat memberikan informasi telah menyelesaikan pelayanan masyarakat

2. Hasil data yang telah diinput akan diproses dan disimpan di bagian penyimpanan data pada bagian sistem pelayanan masyarakat

3. Data yang telah diinput di bagian penginputan data dapat langsung menggunakan data tersebut.

\section{Diagram Alir Data (DAD)}

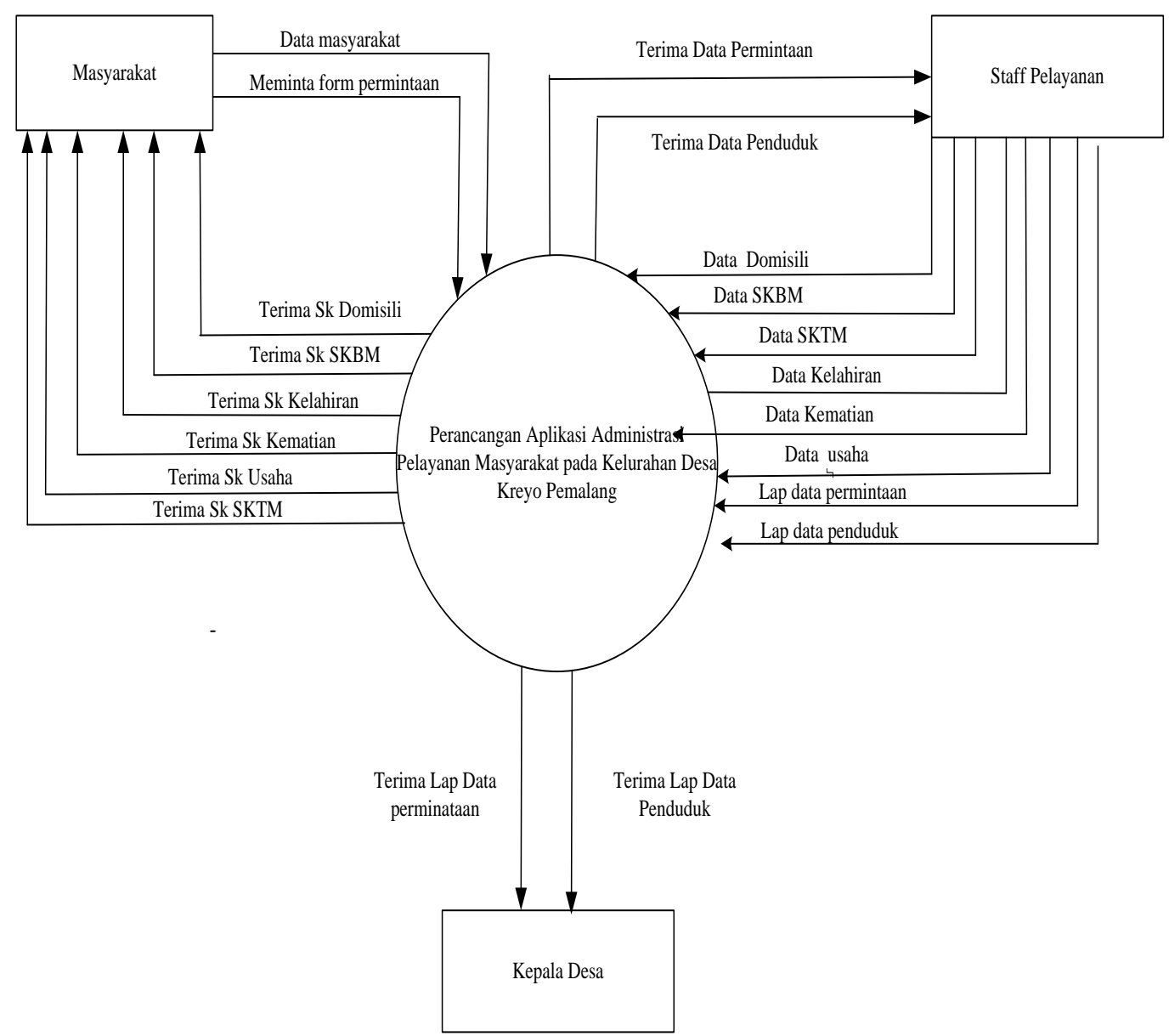

Gambar 1. Diagram Konteks Sistem Usulan 

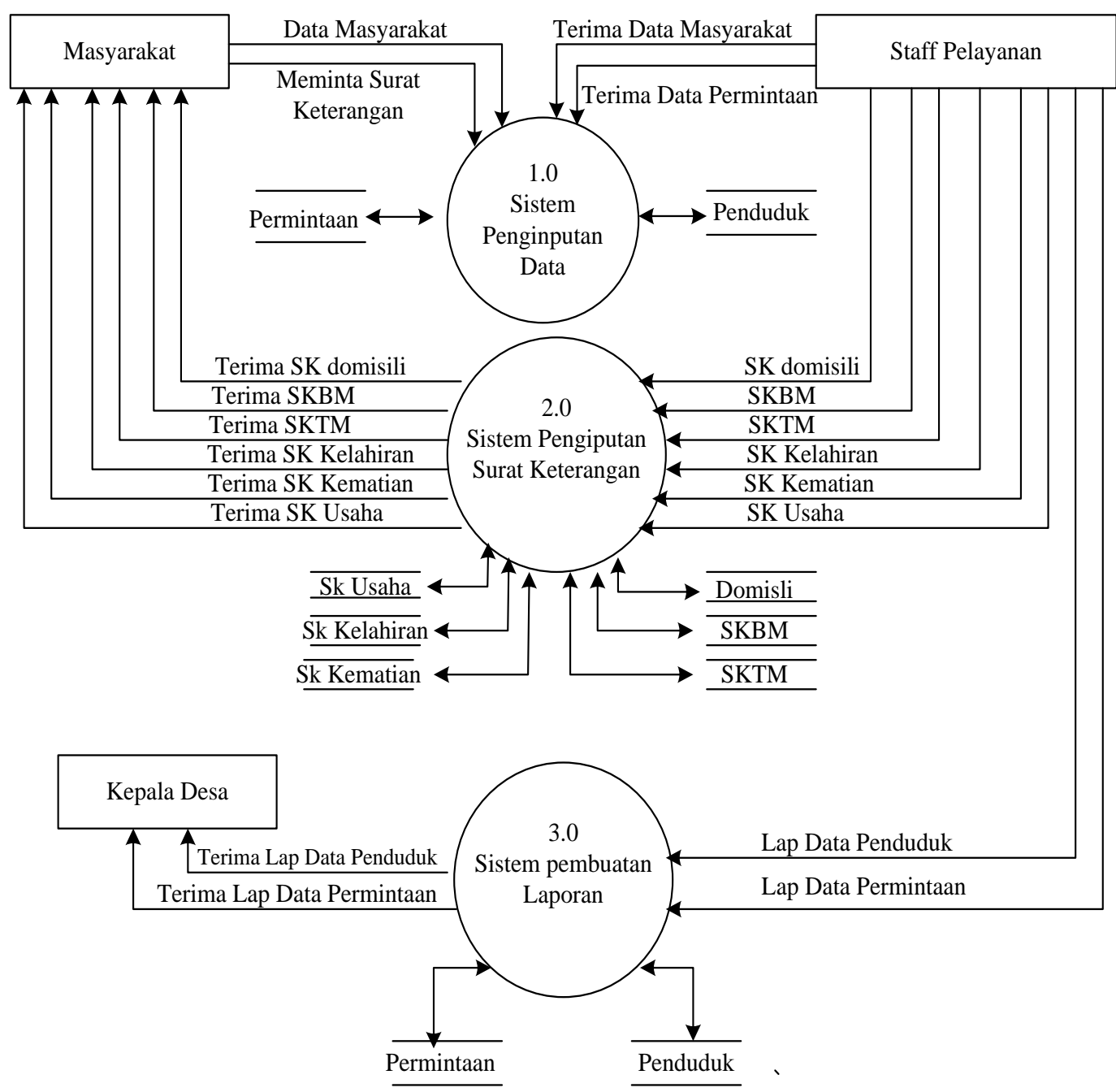

Gambar 2. Diagram Nol Sistem Usulan

\section{Entity Relationship Diagram (ERD)}

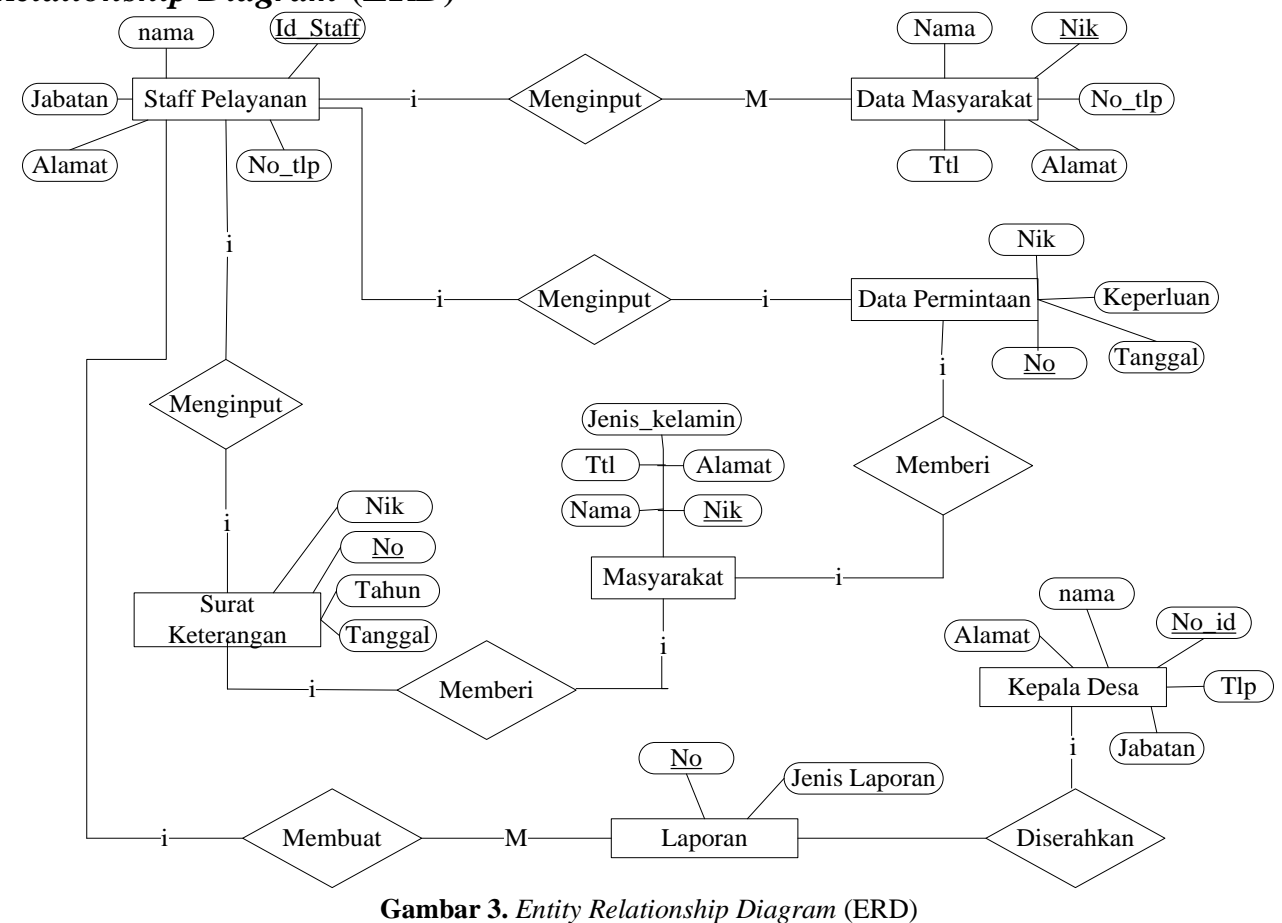


Tampilan Layar Login

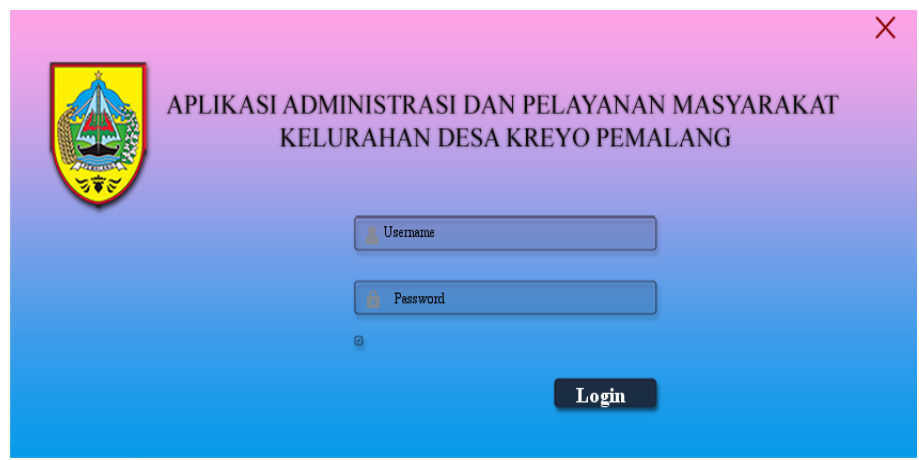

Gambar 4. Menu Login

Pada menu login adalah sebagai akses menuju ke menu utama dengan memasukkan username dan password

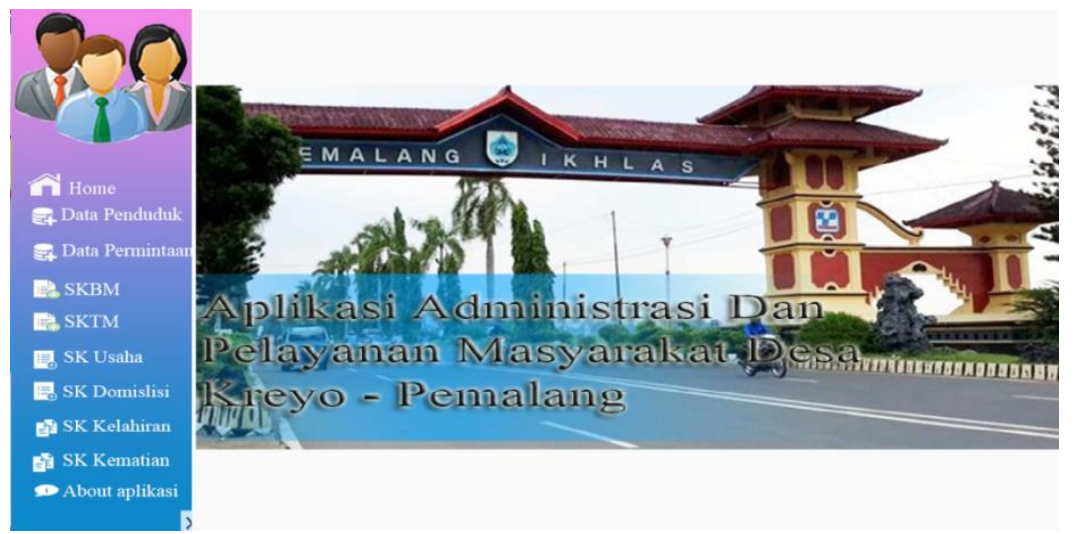

Gambar 5. Menu Utama

Setelah berhasil pada menu login maka staff pelayanan akan beralih pada menu utama yang menyediakan berbagai menu yang dapat diakses oleh admin

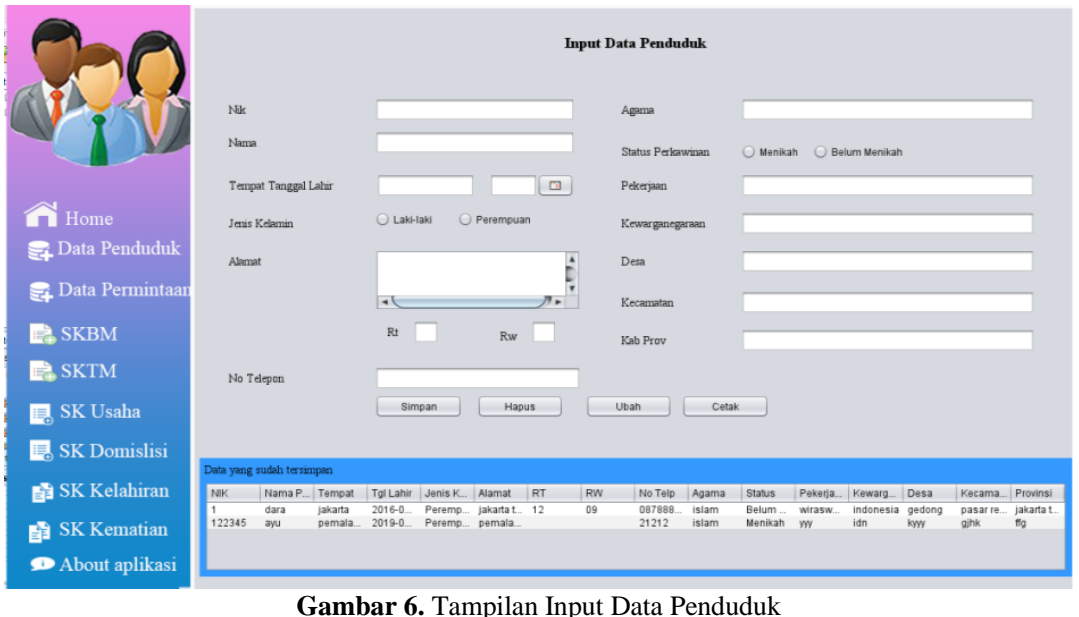

Pada menu input data penduduk staff pelayanan akan menginput data penduduk yang kemudian secara otomatis akan disimpan di Database 


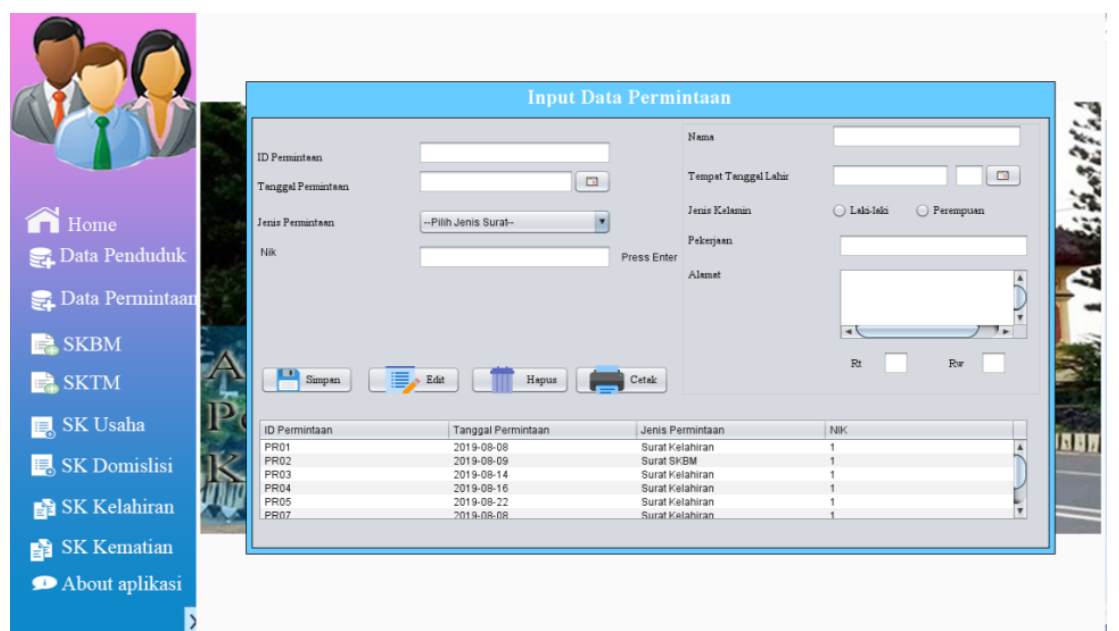

Gambar 7. Tampilan Input Data Permintaan

Pada menu input data permintaan staff pelayanan akan menginput data permintaan apabila masyarakat akan membuat surat keterangan

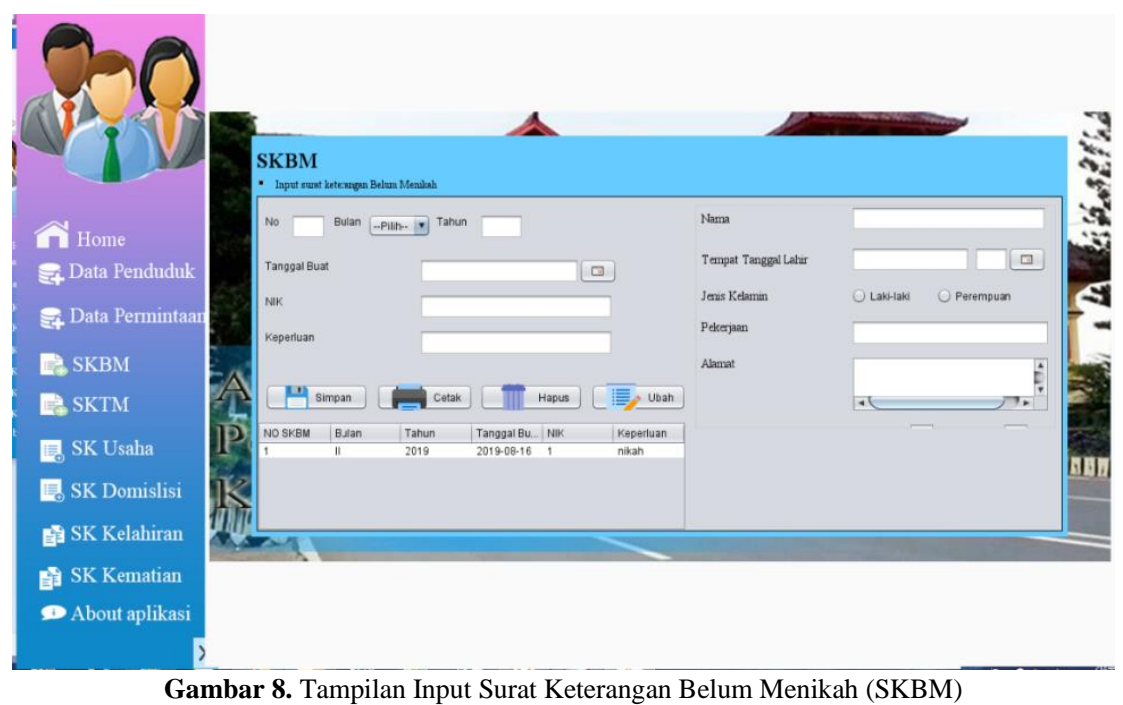

Pada menu input surat keterangan belum menikah staff pelayanan akan menginput data dari masyarakat atau data dari pemohon.

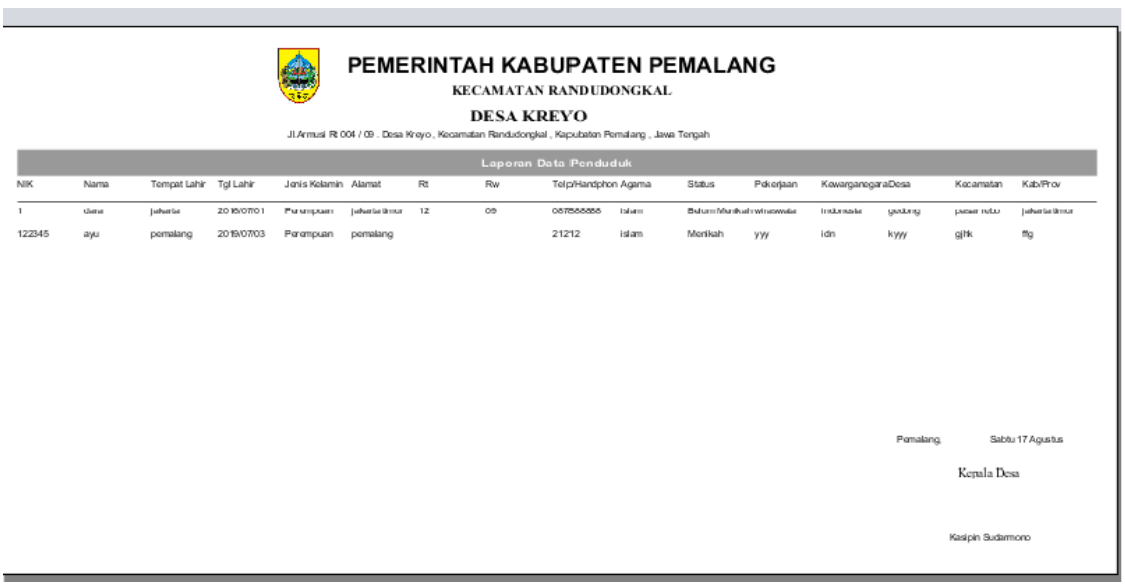

Gambar 9. Tampilan Laporan Data Penduduk

Pada menu hasil laporan akan menampilkan semua data penduduk atau data permintaan yang telah diinput oleh staf pelayanan 


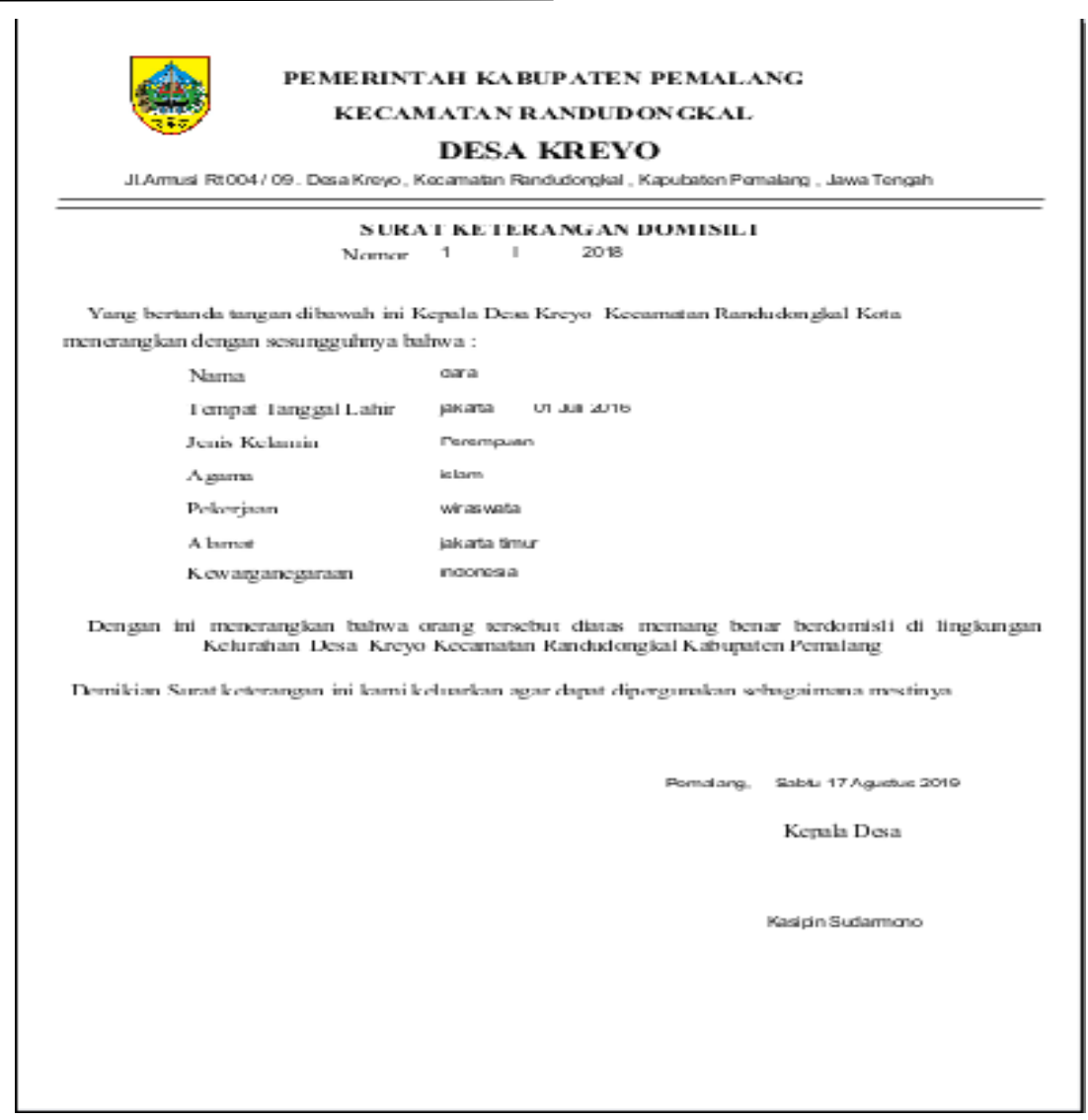

Gambar 10. Tampilan Laporan Surat Keterangan

Pada keluaran surat keterangan yang diminta oleh masyarakat akan bias langsung dicetak oleh staf pelayanan

\section{SIMPULAN}

Dengan dibuatnya sistem aplikasi administrasi kinerja staff akan lebih efisien dan efektif, aplikasi ini dapat memberikan kemudahan staff kelurahan dalam melakukan pekerjaan baik pelayanan masyarakat maupun pembuatan laporan karena sistem pengarsipan sebelumnya masih menggunakan sistem manual yang tidak terhubung dengan database yang menyebabkan kinerja staff pelayanan tidak efektif dan efisien. Dalam sistem aplikasi ini staff mempunyai hak akses dengan user dan password yang sudah ditentukan kemudian didalam sistem tersebut terdapat beberapa menu untuk membuat surat permintaan dari masyarakat, dan terdapat laporan yang secara otomatis disimpan didalam database dan dapat diserahkan kepada Kepala Desa dan masyarakat secara cepat dam efisien. Dengan sistem aplikasi administrasi dan pelayanan masyarakat yang terhubung dengan database masyarakat akan lebih cepat mendapatkan surat yang dibutuhkan baik surat baru ataupun surat yang sudah lama, staff pelayanan tidak perlu lagi untuk mencari data secara manual didalam aplikasi tersebut tersedia data-data pengarsipan dari tahun ke tahun.

\section{DAFTAR PUSTAKA}

Moenir. (2011). Standar Pelayanan Public Pemerintah Daerah Indonesia. Kreasi Wacana. Mulyadi. (2010). Sistem Akuntansi. Salemba Empat.

Sari, Putri. (2016). Perancangan Sistem Informasi pelayanan Masyarakat pada PTSP Kelurahan Ragunan Jakarta Selatan. Universitas Indraprasta PGRI Jakarta.

Sutanta, Edhy. (2013). Sistem Informasi Manajemen (Vol. 5, Issue 2). Graha Ilmu. 